\title{
Litigation risks despite guideline adherence for acute spinal cord injury: time is spine
}

\author{
Daniel Rafter, MD, ${ }^{1}$ Ranveer Vasdev, BS, ${ }^{1}$ Duncan Hurrelbrink, BA, ${ }^{1}$ Mark Gormley III, BS, ${ }^{1}$ \\ Tabitha Chettupally, BS, ${ }^{1}$ Francis X. Shen, JD, PhD, ${ }^{2,3}$ and Uzma Samadani, MD, PhD ${ }^{1,4}$
}

\begin{abstract}
1Department of Bioinformatics and Computational Biology, University of Minnesota, Minneapolis, Minnesota; 2University of Minnesota Law School, Minneapolis, Minnesota; ${ }^{3}$ Department of Psychiatry, Massachusetts General Hospital, Boston, Massachusetts; and ${ }^{4}$ Neurosurgery Section, Department of Neurosurgery, Minneapolis VA, Minneapolis, Minnesota
\end{abstract}

\begin{abstract}
OBJECTIVE Current guidelines do not specify timing for management of acute spinal cord injury (aSCI) due to lack of high-quality evidence supporting specific intervals for intervention. Randomized prospective trials may be unethical. Nonetheless, physicians have been sued for delays in diagnosis and intervention.
\end{abstract}

METHODS The authors reviewed both the medical literature supporting the guidelines and the legal cases reported in the Westlaw and Lexis Advance databases from 1972 to 2018 resulting in awards or settlements, to identify whether surgeons are vulnerable to litigation despite the existence of guidelines not mandating specific timing of care.

RESULTS Timing of intervention was related to claims in 59 (36\%) of 163 cases involving SCl. All 22 trauma cases identified cited timing of intervention, sometimes related to delayed diagnosis, as a reason for the lawsuit. The mean award of 10 cases in which the plaintiffs' awards were disclosed was $\$ 4,294,384$. In the majority of cases, award amounts were not disclosed.

CONCLUSIONS Because conduct of a prospective, randomized trial to investigate surgical timing of intervention for aSCI may not be achievable, evidence-based guidelines will be unlikely to mandate specific timing. Nonetheless, surgeons who unreasonably delay intervention for aSCI may be at risk for litigation due to treatment delay. This is increasingly likely in an environment where "complete" SCI is difficult to verify. SCI may at some point be recognized as a surgical emergency, as brain injury generally is, despite a lack of prospective randomized trials supporting this implementation, challenging the feasibility of the US trauma infrastructure to provide care for these patients.

https://thejns.org/doi/abs/10.3171/2020.8.FOCUS20607

KEYWORDS litigation; spinal cord injury; timing; intervention; surgical decompression

$\mathrm{T}$ RAUMATIC spinal cord injury (SCI) is a devastating disease process with significant morbidity and mortality. For those patients who survive the injury, approximately $32.5 \%$ are left with complete paraplegia or tetraplegia. These neurological deficits not only incur significant costs, but also dramatically impair patients' ability to work and reduce their life expectancy. For patients with incomplete motor loss (66.8\%), the average yearly expenses directly attributed to their injury are $\$ 375,196$ for the first year and \$45,572 thereafter. As the level of impairment increases, the cost increases, with high cervical tetraplegia incurring $\$ 1,149,629$ in year 1 and $\$ 199,637$ annually after that. In addition, acute SCI (aSCI) patients have an employment rate in their first year postinjury of $18 \%$ compared to $67 \%$ preinjury, and this only improves to an average of $32 \% 40$ years postinjury. The compound- ing effect of increased expenses and the inability to work can leave patients financially compromised. Furthermore, aSCI patients have shorter life expectancies, with incomplete motor loss patients living an average of 34.8 years, high cervical tetraplegic patients 20.6 years, and ventilator-dependent patients 8.6 years postinjury. ${ }^{1}$ Therefore, a focus on interventions that optimize patient outcomes is critical to improving SCI management.

The timing of intervention and its impact on patient outcomes is one aspect of aSCI management that has been discussed extensively. ${ }^{2,3}$ In 1911, the novel theory that decompressing the spinal cord early would allow blood products and necrotic debris to extravasate before the onset of secondary injury was proposed. ${ }^{4}$ World War I and World War II then expanded interest in aSCI research. ${ }^{5}$ In 1965, the early hypothermic treatment of SCIs in ani-

ABBREVIATIONS AIS = American Spinal Injury Association Impairment Scale; aSCI = acute SCl; aSDH = acute subdural hematoma; ATCCS = acute traumatic central cord syndrome; CNS = Congress of Neurological Surgeons; $\mathrm{SCl}=$ spinal cord injury.

SUBMITTED July 1, 2020. ACCEPTED August 18, 2020.

INCLUDE WHEN CITING DOI: 10.3171/2020.8.FOCUS20607. 
mal subjects demonstrated significant recovery of sensory and motor function. ${ }^{6}$ Other studies evaluated the use of steroids within 3 hours of aSCI; ${ }^{7}$ however, due to research ethics laws established via the Nuremberg Code in 1948, no prospective study could be effectively or ethically replicated in human trials. ${ }^{8}$ Isadore Tarlov, in 1972, wrote that "precious time should not be lost . . . to immediately decompress the spinal cord." In 1990, Bracken and Collins demonstrated a small therapeutic benefit in patients with SCI who received supraphysiological doses of methylprednisolone within 8 hours of injury, facilitating further discussion around the idea of early management. ${ }^{10}$

A role for early surgical decompression in aSCI is suggested by pathophysiology. Histologically, the acute phase of SCI is characterized by inflammation and ischemia, while the subacute/chronic phase demonstrates cytotoxicity, scarring, and vascular compromise. ${ }^{11}$ It is plausible that early surgical decompression could mitigate secondary injury, leading to improved clinical outcomes, ${ }^{3}$ although approximately half of patients do not receive surgery within 24 hours of SCI. ${ }^{12,13}$ Despite the discordance between clinical preference and practice, some literature suggests that early surgical decompression can improve functional neurological recovery. ${ }^{3}$ The prospective STASCIS (Surgical Timing in Acute Spinal Cord Injury Study) trial found earlier intervention ( $<24$ hours) was associated with an American Spinal Injury Association Impairment Scale (AIS) grade improvement of more than 2 in patients with cervical aSCI without an increased risk of operative complications. ${ }^{14}$ A Canadian prospective study found that early surgical intervention ( $<24$ hours) for aSCI significantly improved AIS motor score by more than 2 grades when compared to delayed intervention. ${ }^{15}$ Early surgical intervention (8-24 hours after injury) has also demonstrated safety, feasibility, and the potential to improve functional recovery while lowering the cost of long-term care. ${ }^{16}$

The establishment of surgical guidelines for neurological pathologies in the US is guided by associations, including the Congress of Neurological Surgeons (CNS) and AO Spine. Both have published several evidence-based guidelines on the topic that are the result of a rigorous, multidisciplinary review of the literature by experts in the field. Currently, they do not recommend definitive guidelines regarding the timing of aSCI intervention due to insufficient quality of evidence and the paucity of prospective studies. However, guidelines on neurosurgical conditions such as epidural and subdural hematomas are supported with retrospective studies alone as prospective trials are potentially unethical. For example, immediate surgical intervention is recommended for the management of some acute subdural hematomas (aSDHs). ${ }^{17}$ These guidelines reflect the outcomes of several retrospective studies demonstrating improved mortality rates for early ( $<2$ hours) surgical management of aSDH.

SCI is one of the most prevalent pathologies litigated for malpractice in the US due to the multifaceted and heterogeneous nature of SCI and risk of complications. Between 2010 and 2014, the average settlement from SCI malpractice cases was $\$ 2.3$ million, with case proceedings taking 4.5 years for completion when ruling in favor of the defendants. ${ }^{18}$ From a systematic analysis of 569 cases related to SCI malpractice, cases citing diagnostic and operative delay were more likely to rule in favor of the plaintiff. Additionally, physicians were more likely to lose their case and plaintiffs to receive larger awards when patients sustained catastrophic outcomes. ${ }^{19}$ In this review we evaluate whether current guidelines concerning the timing of aSCI surgical management render spinal surgeons vulnerable to risk of litigation. In addition, we discuss the feasibility of caring for these patients in the current healthcare system.

\section{Methods}

\section{Surgical Guideline Selection}

Eligible guidelines focused on the treatment of neurological conditions in the US. Guidelines without a spinal cord pathology ruling and those pertaining exclusively to atraumatic or chronic pathologies, such as oncological masses and demyelinating disorders, were excluded. Recommendations relevant to both pediatric and adult populations were allowed. Guidelines published solely in a language other than English or derived from a governing body without jurisdiction in the US were not eligible. This search identified two premier guideline sources: CNS and AO Spine.

\section{Surgical Guideline Search}

A systematic review of the selected guideline sources was then performed chapter by chapter, or publication by publication, for the keywords "acute Spinal Cord Injury and/or aSCI," "Surgery and/or Intervention," and "early and/or timing." Peer-reviewed publications cited in the selected guidelines via these screening criteria were accessed for review. Those that mentioned timing were then retained for analysis.

Features extracted from the publications included publication year, study design, pathology investigated, number of subjects, the interval for timing criteria, key results, and the class of evidence the conclusions provided. Support for early intervention included outcomes such as improved AIS grade, decreased mortality, fewer complications, and shorter length of stay. ${ }^{20}$ Class of evidence was determined utilizing a methodology recommended by the CNS. ${ }^{21}$

\section{Malpractice Case Extraction}

The malpractice lawsuits examined in our review were retrieved from searches in the Lexis Advance and Westlaw databases. While both databases are useful tools for accessing legal cases in the US, they are not comprehensive and thus may not be fully representative of the spectrum of similar cases.

In Lexis Advance, three searches were performed. First, a Boolean search in the "All Healthcare Law Cases" database was run using the operative terms "summary ("spinal cord injury") or core-terms ("spinal cord injury")," meaning the phrase "spinal cord injury" must appear in the summary or core-terms segments of lawsuits. Second, a further full-text Boolean search was run using the function "medical malpractice" /p "spinal cord injury" /p (diagnos! or misdiagnos!), meaning the phrase "medical malpractice" and the phrase "spinal cord injury" must appear in the same paragraph. In addition, the paragraph 


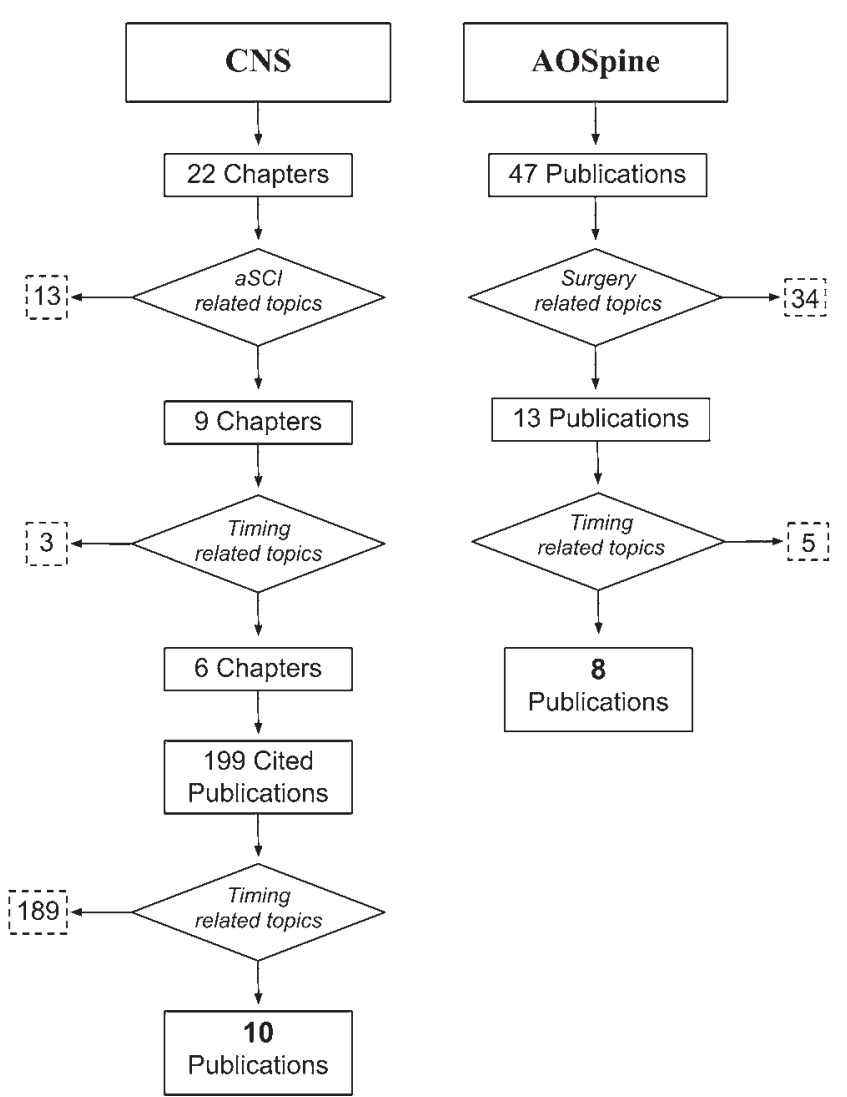

FIG. 1. Neurosurgical guideline flowchart depicting the publication selection and categorization for analysis. From the CNS 2013 guidelines and AO Spine 2017 guidelines.

must also contain words with the root diagnos! or misdiagnos!. Note that " $/ p$ " signifies the same paragraph and the exclamation point is a root extender. Third, a final Lexis Advance blanket search was made in the "All Healthcare Law Jury Verdicts \& Settlements" database using the operation "spinal cord injury" \& "medical malpractice," which is a full-text search for documents containing the phrase "spinal cord injury" and the phrase "medical malpractice" in the same document.

In Westlaw, a first Boolean search in the "Health Law Cases" database was performed using the operation SY,DI("medical malpractice" \& "spinal cord injury"). This is a field search, meaning the phrase "spinal cord injury" must appear in either the synopsis field (abbreviated SY) or digest field (abbreviated DI) to satisfy the search. A second Boolean search was performed using the operation "medical malpractice" /p "spinal cord injury"/p (diagnos! Or misdiagnos!), which is a full-text search that finds the phrase "medical malpractice" and the phrase "spinal cord injury" appearing in the same paragraph. In addition, the paragraph must also contain words with the root diagnos! or misdiagnos!. A final Westlaw full-text search in the "Health Law Jury Verdicts \& Settlements" database was performed using the operation "spinal cord injury" and "medical malpractice," which looked for the phrase "spinal cord injury" and the phrase "medical malpractice" used in the same document.

\section{Malpractice Case Sorting}

The cases identified were then compiled and underwent a preliminary analysis. Duplicate cases and cases containing incomplete information, such as adequate details of the alleged medical negligence or clinical outcome, were thrown out. We then sorted the lawsuits into five mutually exclusive categories: 1) surgical, in which the nature of the claim stemmed from a perceived surgical mistake; 2) degenerative, in which the plaintiff's illness stemmed from a degenerative illness; 3 ) diagnostic, in which the plaintiff argues that the defendant or defendants did not reach the correct diagnosis in time; 4) traumatic, in which the correct diagnosis was made but the plaintiff argues that the defendant failed to provide appropriate trauma care; and 5) other, for lawsuits that did not fit into the other defined categories or were unique in some aspects that set them apart. Mention for timing of care, year and state of filing, key arguments, and award settlements were extracted, when available.

\section{Results \\ Guideline Characteristics}

Our query identified six CNS "Guidelines for the Management of Acute Cervical Spine and Spinal Cord Injuries 2013" (chapters 10-13, 17-18) that met our inclusion criteria (Fig. 1). ${ }^{22}$ The analyzed chapters referenced 199 peer-reviewed publications and 10 directly investigated the timing of surgical intervention and its impact on aSCI recovery. They were published between 1991 and 2011, ranging from single case reports to prospective observational trials, and were all evidence class III. A complete output of extracted features for these publications is displayed in Table 1.

Similarly, we identified 8 of the 47 publications cited in the AO Spine's "A Clinical Practice Guideline for the Management of Patients With Acute Spinal Cord Injury and Central Cord Syndrome: Recommendations on the Timing ( $\leq 24$ hours vs $>24$ hours) of Decompressive Surgery," which met our inclusion criteria (Fig. 1). ${ }^{23}$ Publications were published between 1954 and 2015 and included case reports, retrospective reviews, prospective observational trials, and a single randomized controlled study. The evidence class for all publications was also class III.

\section{Legal Database Output}

Our queries identified 221 cases in Westlaw and 140 cases in Lexis Advance. Of those, 198 cases were found to be duplicates or contained incomplete information, and thus were excluded. The remaining 163 cases were retained for evaluation (Fig. 2). Cases were filed between 1972 and 2018 and the most common state was California (23\%), followed by Florida (6\%) and Massachusetts (6\%). The timing of care was noted in the available filing documents in $36 \%$ of all cases identified. Figurative representation of the distribution of case categories is shown in Fig. 3.

Categorization based on 5 key features of the malpractice argument demonstrated 70 surgical cases, 5 degenerative cases, 30 diagnostic cases, 22 traumatic cases, and 36 other cases. Cases focused on surgical error, degenerative disease, and "other" were filed between 1989 and 2018, 


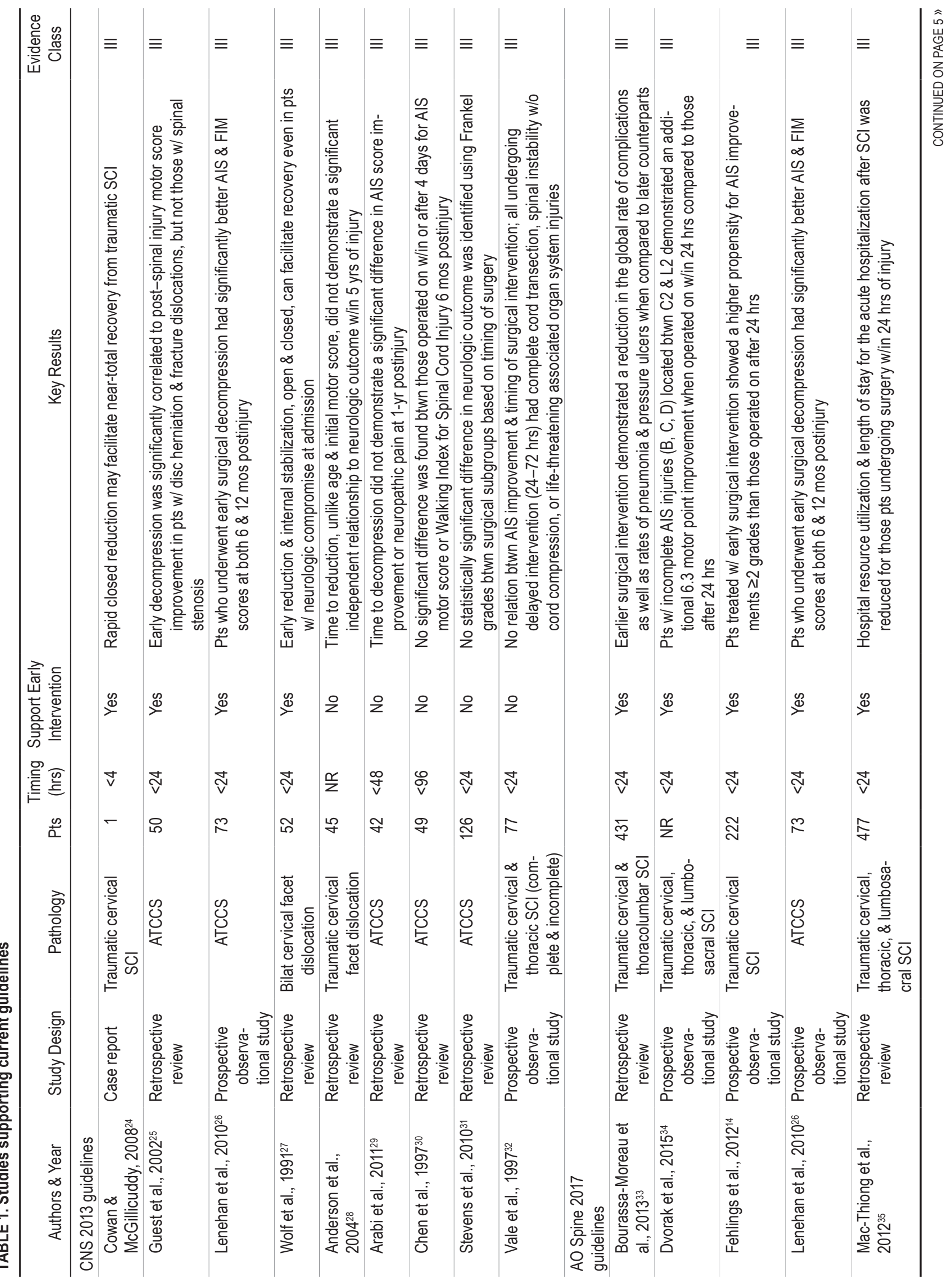


Rafter et al.
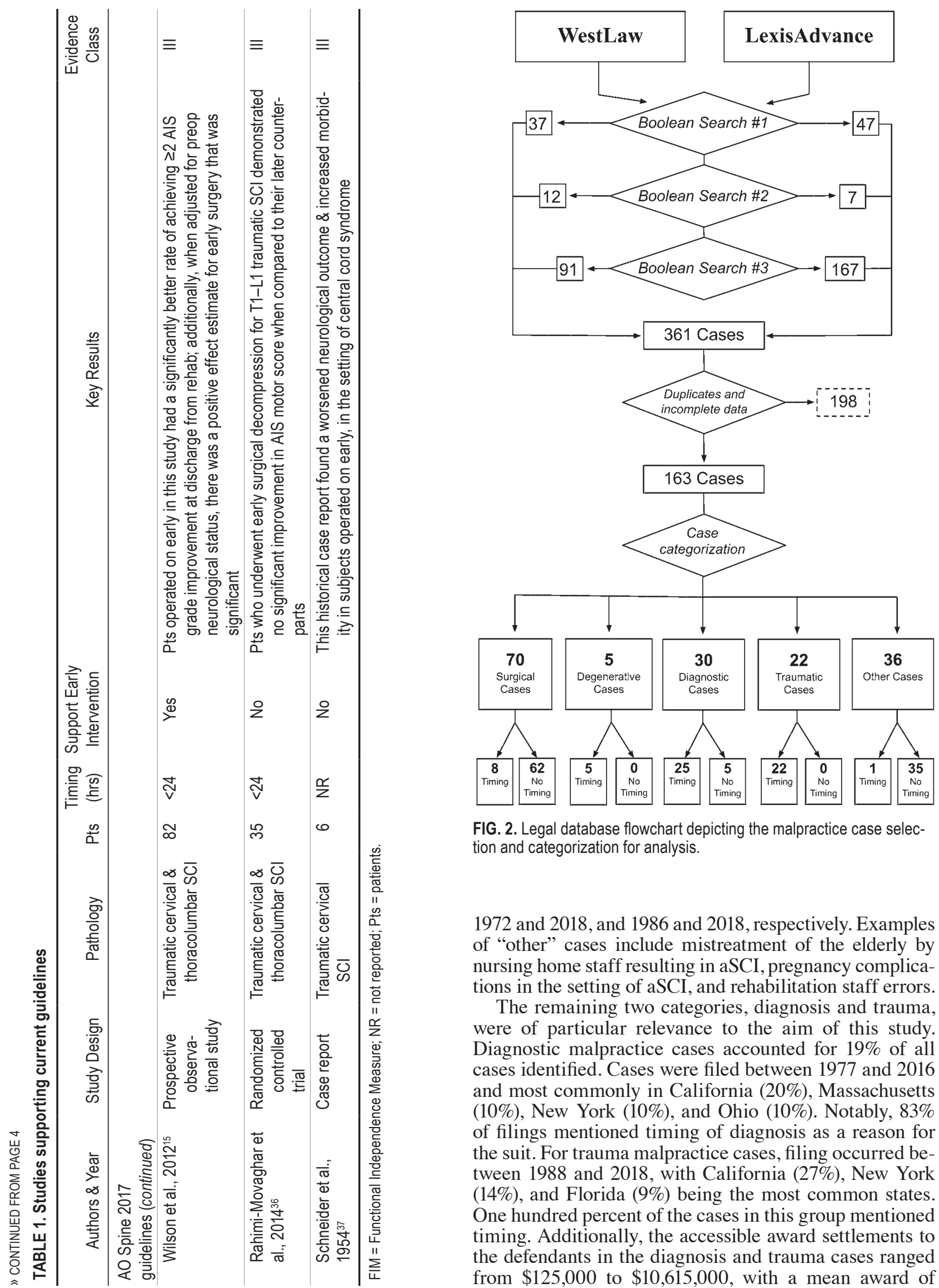

FIG. 2. Legal database flowchart depicting the malpractice case selection and categorization for analysis.

1972 and 2018, and 1986 and 2018, respectively. Examples of "other" cases include mistreatment of the elderly by nursing home staff resulting in aSCI, pregnancy complications in the setting of aSCI, and rehabilitation staff errors.

The remaining two categories, diagnosis and trauma, were of particular relevance to the aim of this study. Diagnostic malpractice cases accounted for $19 \%$ of all cases identified. Cases were filed between 1977 and 2016 and most commonly in California (20\%), Massachusetts $(10 \%)$, New York (10\%), and Ohio (10\%). Notably, $83 \%$ of filings mentioned timing of diagnosis as a reason for the suit. For trauma malpractice cases, filing occurred between 1988 and 2018, with California (27\%), New York $(14 \%)$, and Florida (9\%) being the most common states. One hundred percent of the cases in this group mentioned timing. Additionally, the accessible award settlements to the defendants in the diagnosis and trauma cases ranged from $\$ 125,000$ to $\$ 10,615,000$, with a mean award of 


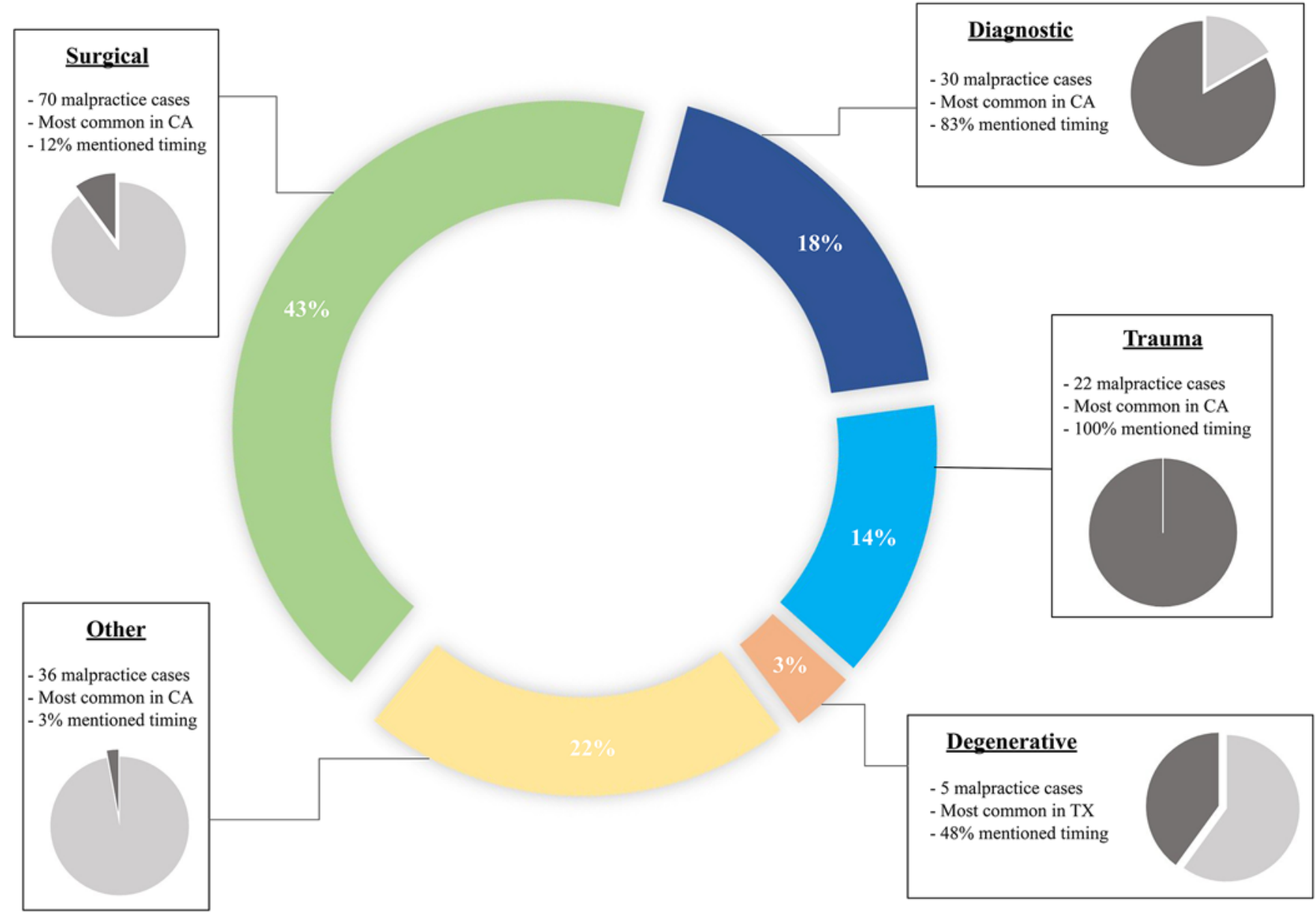

FIG. 3. Pie chart for SCI malpractice cases. Categorization based on the key features of the negligence accusations: surgical, diagnostic, trauma, degenerative, and other. Secondary pie charts depict the portion of cases in each category that were related to the timing of care. $\mathrm{CA}=$ California; $\mathrm{TX}=$ Texas.

$\$ 4,294,384$ (Table 2). Of note, a majority of settlements were not publicly available as they were settled out of court or currently ongoing.

\section{Discussion}

The optimal timing of surgical intervention for aSCI is frequently debated. While more than $80 \%$ of neurological and orthopedic spine surgeons favor early surgical decompression, ${ }^{12}$ national guidelines do not endorse a specific window of timing for intervention. Two US-based neurosurgical aSCI guidelines, CNS's 2013 guidelines and AO Spine's 2017 guidelines, have determined that the current body of data favoring early surgical decompression for aSCI treatment is insufficient given the lack of randomized prospective controlled trials and quality of supporting evidence. ${ }^{22,23}$

\section{CNS Guidelines}

Discussion of surgical intervention timing in the 2013 CNS guidelines primarily occurred in Chapter 17: "Management of Acute Traumatic Central Cord Syndrome (ATCCS)." The authors argued that the heterogeneity of
ATCCS presented barriers to the investigation of the role that early surgical intervention plays in improving postoperative outcomes. ${ }^{38} \mathrm{~A}$ key study referenced by CNS authors was a retrospective study of ATCCS subjects, which suggested no benefit of early surgical intervention. The AIS grade scores of these patients were collected over a 5-year period and compared using a statistical model based on the date to measure correlation between variables and motor score improvement. While the authors were able to isolate single variable effects on postoperative outcomes using this model, the study's subject cohort was notably heterogenous. The authors address this as a limitation of their study. As such, it may be difficult to ascertain a demonstrated benefit of early surgical intervention using this statistical model. ${ }^{28}$ Notably, a recent meta-analysis evaluating 10 studies demonstrated benefit for ATCCS secondary to vertebral fracture, dislocation, traumatic disc herniation, or instability after early decompression. ${ }^{39}$ Nonetheless, the current evidence is primarily retrospective and observational. The argument has been made that prospective randomized studies are needed to evaluate the impact of surgical timing on postoperative outcomes. Given the significant infrastructure required to support 
TABLE 2. Malpractice case examples with award settlements

\begin{tabular}{|c|c|c|c|}
\hline Case Details & Argument & State & Award \\
\hline $\begin{array}{l}\text { Plaintiff was seen for new-onset pain in their right upper extremity. The defendant diagnosed } \\
\text { the plaintiff w/ radiculopathy \& recommended an anterior cervical discectomy. The surgery } \\
\text { was performed \& immediately postoperatively the pt noted complete loss of sensation from } \\
\text { the midchest down. Surgical revision did not occur until } 6 \text { hrs after the discovery of the new } \\
\text { sensory loss. The plaintiff was left w/ chronic neurologic deficits. }\end{array}$ & $\begin{array}{l}\text { The delay in interven- } \\
\text { tion resulted in } \\
\text { irreversible spinal } \\
\text { cord damage }\end{array}$ & Ohio & $\$ 10,615,000$ \\
\hline $\begin{array}{l}\text { Plaintiff, who had preexisting cerebral palsy, was admitted to the hospital with new-onset } \\
\text { left-sided weakness. The defendants involved in the plaintiff's case did not diagnose him w/ } \\
\text { ruptured discs from C } 3 \text { to C } 5 \text { until } 11 \text { days after presentation. At that point, permanent dam- } \\
\text { age had occurred to the cervical spinal cord. The incident occurred over a holiday, when the } \\
\text { defendants had reduced hrs \& failed to diagnose \& treat the plaintiff's condition despite the } \\
\text { documented neurological deterioration in the electronic medical record. The plaintiff was left } \\
\text { quadriplegic. }\end{array}$ & $\begin{array}{l}\text { The delay in diagnosis } \\
\& \text { intervention re- } \\
\text { sulted in irreversible } \\
\text { spinal cord damage }\end{array}$ & California & $\$ 8,148,137$ \\
\hline $\begin{array}{l}\text { Plaintiff underwent an initiation ceremony for a Masonic society during which he was blind- } \\
\text { folded \& bounced by several members on a canvas blanket. During the ceremony the plaintiff } \\
\text { landed on his head, suffering a cervical spine injury. Paramedics on scene misdiagnosed } \\
\text { the plaintiff as having a psychological episode \& thus he was not put in cervical precautions. } \\
\text { Upon arrival at the hospital, the plaintiff did not receive spinal imaging or neurosurgery con- } \\
\text { sultation. Two days postinjury, the plaintiff's nurse noted progressive weakness in the upper } \\
\text { extremities. At that time, repeat imaging was performed \& demonstrated edema of the spinal } \\
\text { cord. The plaintiff was left quadriplegic. }\end{array}$ & $\begin{array}{l}\text { The failed prehospital } \\
\text { precautions, radio- } \\
\text { graphic examina- } \\
\text { tion, neurosurgical } \\
\text { consultation, \& in- } \\
\text { tervention resulted } \\
\text { in irreversible spinal } \\
\text { cord damage }\end{array}$ & Florida & $\$ 8,000,000$ \\
\hline $\begin{array}{l}\text { Plaintiff, a } 26 \text {-year-old man, presented to the office of his primary care physician, defendant, } \\
\text { complaining of unremitting back pain. At that time the plaintiff was being treated for a Staphy- } \\
\text { lococcus infection \& the defendant believed he may have developed an epidural spinal } \\
\text { abscess. The defendant ordered blood tests, prescribed an antiinflammatory, \& directed the } \\
\text { plaintiff to seek medical attention in the emergency room if pain worsened or he developed } \\
\text { neurologic symptoms. Later that day, the plaintiff's pain worsened \& he was evaluated in } \\
\text { the emergency room. An MRI confirmed the presence of an epidural abscess that was } \\
\text { treated surgically. The following day, the defendant visited the plaintiff \& discovered he was } \\
\text { paralyzed from the waist down. The plaintiff never regained function of his lower extremities, } \\
\text { bowel, or bladder. }\end{array}$ & $\begin{array}{l}\text { The delay in confirma- } \\
\text { tory diagnosis \& } \\
\text { adequate interven- } \\
\text { tion resulted in } \\
\text { irreversible spinal } \\
\text { cord damage }\end{array}$ & California & $\$ 4,724,719$ \\
\hline $\begin{array}{l}\text { The plaintiff underwent a scheduled anterior discectomy \& cervical fusion to treat a ruptured } \\
\text { disc at C3-4 at a VA hospital by defendant } 1 \text {, the attending neurosurgeon, \& defendant } 2 \text {, the } \\
\text { resident surgeon. During the operation Surgifoam was utilized to mitigate bleeding \& the sur- } \\
\text { gical site was closed. Postoperatively, the plaintiff endorsed loss of motor \& sensory function } \\
\text { below the neck. Follow-up MRI revealed spinal cord compression secondary to Surgifoam. } \\
\text { Defendant } 1 \text { was informed of the plaintiff's condition \& advised defendant } 2 \text { that the sensory } \\
\& \text { motor function would return in time. Defendant } 1 \text { did not evaluate the plaintiff for } 7 \text { days } \\
\text { postoperatively despite no return of function. The plaintiff was left quadriplegic. }\end{array}$ & $\begin{array}{l}\text { The delay in examina- } \\
\text { tion \& failure to } \\
\text { reoperate resulted } \\
\text { in irreversible spinal } \\
\text { cord damage }\end{array}$ & California & $\$ 4,341,919$ \\
\hline $\begin{array}{l}\text { Plaintiff was involved in an MVC \& was arrested after fleeing the scene. During apprehen- } \\
\text { sion, the plaintiff was restrained \& had his face pressed against the officer's vehicle. Upon } \\
\text { arrival at the hospital, radiographic examinations identified cervical spine injury warranting } \\
\text { an Aspen collar for } 6-8 \text { wks. During the plaintiff's hospitalization they sustained an alcohol } \\
\text { withdrawal seizure, fell, \& sustained further cervical injury. Four days after the seizure, the } \\
\text { plaintiff complained of motor \& sensory loss in his upper extremities. The defendants deter- } \\
\text { mined he could be discharged once able to ambulate. The following day, the plaintiff was } \\
\text { found to be paralyzed from the neck down. Surgical decompression was performed at that } \\
\text { time. The plaintiff was left quadriplegic. }\end{array}$ & $\begin{array}{l}\text { The delay in diagnosis } \\
\text { \& surgical interven- } \\
\text { tion resulted in } \\
\text { irreversible spinal } \\
\text { cord damage }\end{array}$ & California & $\$ 3,450,000$ \\
\hline $\begin{array}{l}\text { The plaintiff, a 42-year-old man, was participating in an off-road vehicle excursion, hit uneven } \\
\text { ground, \& landed forcefully on the seat. Subsequently, he began experiencing low-back pain } \\
\text { as well as numbness in his bilat lower extremities. Pt was admitted to the hospital with a } \\
\text { probable spinal column fracture \& neurosurgery was consulted. The defendant, a neurosur- } \\
\text { geon, was required to see the pt within } 20 \text { mins of consultation. However, the defendant did } \\
\text { not see the pt until the following day. The plaintiff underwent surgical decompression } 2 \text { days } \\
\text { postinjury. Despite intervention, the plaintiff was left paraplegic. }\end{array}$ & $\begin{array}{l}\text { The delay in examina- } \\
\text { tion \& surgical inter- } \\
\text { vention resulted in } \\
\text { irreversible spinal } \\
\text { cord damage }\end{array}$ & California & $\$ 3,000,000$ \\
\hline
\end{tabular}




\begin{tabular}{|c|c|c|c|}
\hline Case Details & Argument & State & Award \\
\hline $\begin{array}{l}\text { Plaintiff presented to the hospital with new-onset pain \& paresthesias in his bilat upper extremi- } \\
\text { ties. At that time, he was evaluated by defendant } 1 \text {, who suspected carpal tunnel syndrome } \\
\text { as the underlying pathology \& ordered an EMG. Defendant } 2 \text { reviewed the EMG results \& } \\
\text { notified defendant } 1 \text { of the abnormalities found \& suggested additional testing in addition to } \\
\text { a neurosurgical consult. Defendant } 1 \text { did not pursue further evaluation, did not inform the } \\
\text { plaintiff of defendant 2's recommendations, \& discharged them. Six mos later the plaintiff } \\
\text { re-presented w/ progressive symptoms including difficulty extending his It upper extremity \& } \\
\text { bilat lower extremities. Defendant } 3 \text { did not recommend a neurosurgical consult \& discharged } \\
\text { the plaintiff. An evaluation done } 10 \text { mos after onset of symptoms included a neurosurgical } \\
\text { consult \& MRI, which revealed disc herniation at C3-6. At that time, the plaintiff was diag- } \\
\text { nosed w/ hyperreflexia w/ clonus in the lower extremities requiring surgical intervention. The } \\
\text { plaintiff was left w/ multiple chronic neurologic deficits. }\end{array}$ & $\begin{array}{l}\text { The repetitive delay in } \\
\text { diagnosis \& surgical } \\
\text { intervention re- } \\
\text { sulted in irreversible } \\
\text { spinal cord damage }\end{array}$ & Pennsylvania & $\$ 298,979$ \\
\hline $\begin{array}{l}\text { The plaintiff was involved in an MVC \& was ejected from the vehicle. Upon arrival at the hospital } \\
\text { the plaintiff endorsed the loss of motor function in his legs. The emergency medicine physi- } \\
\text { cian examined the plaintiff \& found paralysis from the midchest down. A portable cervical } \\
\text { spine radiograph was ordered, which demonstrated no fracture or abnormality. The on-call } \\
\text { neurosurgeon, defendant, was consulted but was unable to be reached for over an hr \& } \\
\text { ultimately refused to come to the hospital in the middle of the night. The defendant did } \\
\text { order additional imaging of the spine \& asked to be kept informed of any findings. Additional } \\
\text { radiographs were negative for acute pathology. Despite voicing distrust in the findings \& } \\
\text { that they felt there was an undiagnosed fracture, the defendant again refused to come to the } \\
\text { hospital. At 4:00 Am the defendant came in \& evaluated the plaintiff but did not document the } \\
\text { neurological assessment in the EMR. By 7:30 AM the plaintiff had developed numerous motor } \\
\text { \& sensory deficits. }\end{array}$ & $\begin{array}{l}\text { The delay in examina- } \\
\text { tion \& failure to } \\
\text { intervene resulted } \\
\text { in irreversible spinal } \\
\text { cord damage }\end{array}$ & Louisiana & $\$ 240,084$ \\
\hline $\begin{array}{l}\text { Plaintiff, a 36-year-old woman, was involved in a horseback riding accident during which she } \\
\text { was thrown \& landed on her back. Upon arrival at the hospital, radiographic examinations } \\
\text { revealed a T5-6 burst fracture w/ increasing kyphotic deformity. The defendant, an orthope- } \\
\text { dic surgeon on-call, recommended surgery. However, this was not performed until } 18 \text { days } \\
\text { postinjury. The surgery was performed \& the same day reoperation was required to replace } \\
\text { misplaced rods from T1 to T12. The plaintiff was left w/ incomplete paraplegia. }\end{array}$ & $\begin{array}{l}\text { The delay in operation, } \\
\text { in the setting of } \\
\text { increasing kyphotic } \\
\text { deformity, resulted } \\
\text { in irreversible spinal } \\
\text { cord damage }\end{array}$ & California & $\$ 125,000$ \\
\hline
\end{tabular}

$E M G$ = electromyogram; EMR = electronic medical record; MVC = motor vehicle crash.

early spine surgery, its incipient risks, the heterogeneity of neuropathology, and the research protection acts in place, randomized controlled trials are difficult to achieve. As such, current guidelines must rely on class III evidence.

\section{AO Spine Guidelines}

AO Spine guideline authors also acknowledge early surgical intervention for patients with aSCI or ATCCS as a treatment option. They too found that no study has rigorously examined the benefits of early $(<24$ hour) surgical decompression for aSCI and that the role of early surgical management for SCI without instability is unclear. ${ }^{23}$ Citing evidence for contraindications to early surgical decompression, AO Spine authors reference a 1954 case series that found that decompression of an unstable spinal column led to neurological deterioration. However, they did not document the specific time of surgical intervention, and thus there is no record of the proportion of procedures that occurred before and after 24 hours. ${ }^{37}$ The commentary of Stevens et al. on this study notes that surgical practices have improved dramatically since 1954 , and concludes that surgical intervention not only is safe for patients, but also may lead to better neurological recovery. ${ }^{31}$ The AO Spine guidelines referenced 4 studies that indicated that surgical decompression was a significantly predictive variable of postoperative motor and neurological improvement. ${ }^{13,15,26,34}$ A single randomized controlled trial with 35 subjects found no significant neurological benefit to early intervention, but no detriment. ${ }^{36}$ While functional recovery may vary, studies have demonstrated that early surgical intervention was positively associated with shorter hospital stays, lower complication rates, and better utilization of hospital resources. This finding alone is not insignificant for patients with aSCI, including those with complete injuries, as well as the healthcare systems that support them..$^{33,35}$ Additionally, 2 recent pooled meta-analyses indicated that patients with aSCI treated surgically within 24 hours had a significantly better improvement in AIS grade when compared to their counterparts who were treated later. ${ }^{40,41}$ In the absence of recent evidence suggesting that surgical intervention worsens patient outcomes, we propose that early spinal cord intervention should be performed when possible for ATCCS and aSCI.

\section{Litigation Risk}

Not only is the timing of intervention for aSCI a factor 
that impacts a patient's functional outcome, but it is also a critical component to some of the reported malpractice cases. By definition, medical malpractice is when a hospital or healthcare provider causes injury to a patient, through either negligence or omission. The claim must prove a violation of the standard of care, that an injury was caused by negligence, and that the injury resulted in damages. ${ }^{42}$ If a decision to delay surgery is deemed to not meet the standard of care, it must also be shown that the delay in timing caused the resulting injury. With clinical outcomes after aSCI being widely variable, an unfavorable outcome may result, regardless of the subsequent interventions. However, given the emerging evidence reviewed above, it seems plausible that delaying intervention could leave some surgeons vulnerable to malpractice suits. Given the debilitating lifelong consequences of aSCI, arguing that the actions, or lack thereof, of the medical staff may have resulted in disability, loss of income, unusual pain, suffering and hardship, or significant medical expenditure is possible. ${ }^{1}$ Additionally, given the lack of clarity surrounding the timing of surgical intervention for aSCI, it is no surprise that all cases identified in our query for management of trauma included the interval of time to treatment in their filing. While explicit guidelines surrounding this topic will not protect medical professionals from civil lawsuits, they may contribute significantly in negligence lawsuits as the standard of care.

\section{Evolving Understanding of $\mathrm{SCl}$}

The likelihood of increased lawsuits related to surgical timing will increase as our understanding and management capabilities for severe traumatic injuries continue to improve. Restoration of volitional movement with epidural spinal cord stimulation in patients who were previously thought to have "complete" SCI has resulted in an evolving understanding of what constitutes an irreversible injury. ${ }^{43-47}$ As biomarkers are identified elucidating the pathophysiology of SCI enabling differentiation between patients with capacity for recovery and those who are less likely to improve, there will be increased need for infrastructure to support early intervention.

\section{Feasibility of Early Intervention and System Capacity Challenges}

Infrastructural components required to execute timely surgery include the availability of qualified surgeons and nurses, as well as the consolidation of proper equipment and instrumentation. Level 1 and 2 trauma centers are the primary treatment facilities for aSCI, but $16 \%$ of the US population does not live within an hour of such centers. ${ }^{48}$ A minority of trauma centers have specific spine call schedules for neurosurgeons, ${ }^{49,50}$ raising the possibility that some neurosurgeons taking trauma call may not perform complex spine surgery. The economics of healthcare may even dissuade complex spine surgeons from taking trauma call as it would interfere with their ability to provide elective care. A potential concern raised by this review is that if SCI is ultimately treated the way brain injury is, as "a surgical emergency," the number of surgeons who are willing to take trauma call may further decrease. The performance of long, stressful, and technically challenging cases in the middle of the night or at off-hours with suboptimal staffing will further challenge a workforce already highly susceptible to burnout. Systematic solutions, such as the outsourcing of complex spine trauma cases to dedicated spine surgeons or spine centers, may be necessary to manage these patients.

\section{Conclusions}

The guidelines for aSCI management do not mandate a timeline for surgical interventions because there have been relatively few randomized prospective trials addressing the issue. The conduct of such trials may be unethical, as they would be for the management of similar acute brain injuries. Nonetheless, patients have successfully litigated against physicians for delays in management of aSCI. The purpose of this study was to evaluate the gap between guideline recommendations and reported legal judgments to better understand if current guidelines might expose surgeons to litigation risk. Our results suggest that, when safe and possible, surgeons may want to intervene as quickly after the injury as is feasible. As understanding of SCI continues to evolve, and there is increased recognition that few injuries are "complete" or "irreversible," such lawsuits may become more common and more successful. Infrastructural and systemic changes are needed to enable surgeons to be able to provide timely care.

\section{Acknowledgments}

We would like to thank Vicente E. Garces at the University of Minnesota Law Library and Brendan Johnson for their contributions to data collection.

\section{References}

1. DeVivo MJ. Causes and costs of spinal cord injury in the United States. Spinal Cord. 1997;35(12):809-813.

2. Wilson JR, Tetreault LA, Kwon BK, et al. Timing of decompression in patients with acute spinal cord injury: a systematic review. Global Spine J. 2017;7(3 Suppl):95S-115S.

3. Badhiwala JH, Ahuja CS, Fehlings MG. Time is spine: a review of translational advances in spinal cord injury. $\mathrm{J} \mathrm{Neu-}$ rosurg Spine. 2019;30(1):1-18.

4. Allen AR. Surgery of experimental lesion of spinal cord equivalent to crush injury of fracture dislocation of spinal column: a preliminary report. JAMA. 1911;57(11):878-880.

5. Lifshutz J, Colohan A. A brief history of therapy for traumatic spinal cord injury. Neurosurg Focus. 2004;16(1):E5.

6. Albin MS, White RJ, Locke GE. Treatment of spinal cord trauma by selective hypothermic perfusion. Surg Forum. 1965;16:423-424.

7. Ducker TB, Hamit HF. Experimental treatments of acute spinal cord injury. J Neurosurg. 1969;30(6):693-697.

8. Shuster E. Fifty years later: the significance of the Nuremberg Code. N Engl J Med. 1997;337(20):1436-1440.

9. Tarlov I. Acute spinal cord compression paralysis. J Neurosurg. 1972;36(1):10-20.

10. Bracken MB, Shepard MJ, Collins WF, et al. A randomized, controlled trial of methylprednisolone or naloxone in the treatment of acute spinal-cord injury. Results of the Second National Acute Spinal Cord Injury Study. $N$ Engl J Med. 1990;322(20):1405-1411.

11. Fehlings MG. Traumatic spinal cord injury's secondary injury cascade. Spine Universe. Accessed September 15, 2020. https://www.spineuniverse.com/conditions/spinal-cord-injury/ traumatic-spinal-cord-injurys-secondary-injury-cascade 
12. Fehlings MG, Rabin D, Sears W, et al. Current practice in the timing of surgical intervention in spinal cord injury. Spine (Phila Pa 1976). 2010;35(21 Suppl):S166-S173.

13. Ter Wengel PV, Feller RE, Stadhouder A, et al. Timing of surgery in traumatic spinal cord injury: a national, multidisciplinary survey. Eur Spine J. 2018;27(8):1831-1838.

14. Fehlings MG, Vaccaro A, Wilson JR, et al. Early versus delayed decompression for traumatic cervical spinal cord injury: results of the Surgical Timing in Acute Spinal Cord Injury Study (STASCIS). PLoS One. 2012;7(2):e32037.

15. Wilson JR, Singh A, Craven C, et al. Early versus late surgery for traumatic spinal cord injury: the results of a prospective Canadian cohort study. Spinal Cord. 2012;50(11): 840-843.

16. Furlan JC, Noonan V, Cadotte DW, Fehlings MG. Timing of decompressive surgery of spinal cord after traumatic spinal cord injury: an evidence-based examination of pre-clinical and clinical studies. J Neurotrauma. 2011;28(8):1371-1399.

17. Bullock MR, Chesnut R, Ghajar J, et al. Surgical management of acute subdural hematomas. Neurosurgery. 2006;58(3 Suppl):S16-S24

18. Dyrda L. 7 trends in spine surgery malpractice cases $-75 \%$ found in favor of surgeons. Becker's Spine Review. July 5, 2017. Accessed September 15, 2020. https://www.beckersspine.com/spine/item/37340-7-trends-in-spine-surgerymalpractice-cases-75-found-in-favor-of-surgeons.html

19. Daniels AH, Ruttiman R, Eltorai AEM, et al. Malpractice litigation following spine surgery. J Neurosurg Spine. 2017; 27(4):470-475.

20. Kirshblum S, Waring W III. Updates for the International Standards for Neurological Classification of Spinal Cord Injury. Phys Med Rehabil Clin N Am. 2014;25(3):505-517, vii.

21. Congress of Neurological Surgeons. Guideline Development Methodology. Accessed September 15, 2020. https://www. cns.org/guidelines/guideline-development-methodology

22. Guidelines for the management of acute cervical spine and spinal cord injuries. Neurosurgery. 2013;72(Suppl 3):1-259.

23. Fehlings MG, Tetreault LA, Wilson JR, et al. A clinical practice guideline for the management of patients with acute spinal cord injury and central cord syndrome: recommendations on the timing ( $\leq 24$ hours versus $>24$ hours) of decompressive surgery. Global Spine J. 2017;7(3 Suppl):195S-202S.

24. Cowan JA Jr, McGillicuddy JE. Images in clinical medicine. Reversal of traumatic quadriplegia after closed reduction. $N$ Engl J Med. 2008;359(20):2154.

25. Guest J, Eleraky MA, Apostolides PJ, et al. Traumatic central cord syndrome: results of surgical management. J Neurosurg. 2002;97(1 Suppl):25-32.

26. Lenehan B, Fisher CG, Vaccaro A, et al. The urgency of surgical decompression in acute central cord injuries with spondylosis and without instability. Spine (Phila Pa 1976). 2010; 35(21 Suppl):S180-S186.

27. Wolf A, Levi L, Mirvis S, et al. Operative management of bilateral facet dislocation. J Neurosurg. 1991;75(6):883-890.

28. Anderson DG, Voets C, Ropiak R, et al. Analysis of patient variables affecting neurologic outcome after traumatic cervical facet dislocation. Spine J. 2004;4(5):506-512.

29. Aarabi B, Alexander M, Mirvis SE, et al. Predictors of outcome in acute traumatic central cord syndrome due to spinal stenosis. J Neurosurg Spine. 2011;14(1):122-130.

30. Chen TY, Lee ST, Lui TN, et al. Efficacy of surgical treatment in traumatic central cord syndrome. Surg Neurol. 1997; 48(5):435-441.

31. Stevens EA, Marsh R, Wilson JA, et al. A review of surgical intervention in the setting of traumatic central cord syndrome. Spine J. 2010;10(10):874-880.

32. Vale FL, Burns J, Jackson AB, Hadley MN. Combined medical and surgical treatment after acute spinal cord injury: results of a prospective pilot study to assess the merits of aggressive medical resuscitation and blood pressure management. J Neurosurg. 1997;87(2):239-246.

33. Bourassa-Moreau É, Mac-Thiong JM, Ehrmann Feldman $\mathrm{D}$, et al. Complications in acute phase hospitalization of traumatic spinal cord injury: does surgical timing matter? $J$ Trauma Acute Care Surg. 2013;74(3):849-854.

34. Dvorak MF, Noonan VK, Fallah N, et al. The influence of time from injury to surgery on motor recovery and length of hospital stay in acute traumatic spinal cord injury: an observational Canadian cohort study. J Neurotrauma. 2015;32(9): 645-654.

35. Mac-Thiong JM, Feldman DE, Thompson C, et al. Does timing of surgery affect hospitalization costs and length of stay for acute care following a traumatic spinal cord injury? $J$ Neurotrauma. 2012;29(18):2816-2822.

36. Rahimi-Movaghar V, Niakan A, Haghnegahdar A, et al. Early versus late surgical decompression for traumatic thoracic/ thoracolumbar (T1-L1) spinal cord injured patients. Primary results of a randomized controlled trial at one year follow-up. Neurosciences (Riyadh). 2014;19(3):183-191.

37. Schneider RC, Cherry G, Pantek H. The syndrome of acute central cervical spinal cord injury; with special reference to the mechanisms involved in hyperextension injuries of cervical spine. J Neurosurg. 1954;11(6):546-577.

38. Aarabi B, Hadley MN, Dhall SS, et al. Management of acute traumatic central cord syndrome (ATCCS). Neurosurgery. 2013;72(Suppl 2):195-204.

39. Yelamarthy PKK, Chhabra HS, Vaccaro A, et al. Management and prognosis of acute traumatic cervical central cord syndrome: systematic review and Spinal Cord Society-Spine Trauma Study Group position statement. Eur Spine J. 2019; 28(10):2390-2407.

40. Yousefifard M, Rahimi-Movaghar V, Baikpour M, et al. Early versus late spinal decompression surgery in treatment of traumatic spinal cord injuries; a systematic review and meta-analysis. Emergency (Tehran). 2017;5(1):e37.

41. El Tecle NE, Dahdaleh NS, Bydon M, et al. The natural history of complete spinal cord injury: a pooled analysis of 1162 patients and a meta-analysis of modern data. J Neurosurg Spine. 2018;28(4):436-443.

42. Danzon PM. Medical Malpractice: Theory, Evidence, and Public Policy. Harvard University Press; 1985.

43. Darrow D, Balser D, Netoff TI, et al. Epidural spinal cord stimulation facilitates immediate restoration of dormant motor and autonomic supraspinal pathways after chronic neurologically complete spinal cord injury. J Neurotrauma. 2019; 36(15):2325-2336.

44. Pino IP, Hoover C, Venkatesh S, et al. Long-term spinal cord stimulation after chronic complete spinal cord injury enables volitional movement in the absence of stimulation. Front Syst Neurosci. 2020;14:35.

45. Gill ML, Grahn PJ, Calvert JS, et al. Neuromodulation of lumbosacral spinal networks enables independent stepping after complete paraplegia. Nat Med. 2018;24(11):1677-1682.

46. Atkinson DA, Sayenko DG, D'Amico JM, et al. Interlimb conditioning of lumbosacral spinally evoked motor responses after spinal cord injury. Clin Neurophysiol. 2020;131(7): $1519-1532$.

47. Arpin DJ, Ugiliweneza B, Forrest G, et al. Optimizing neuromuscular electrical stimulation pulse width and amplitude to promote central activation in individuals with severe spinal cord injury. Front Physiol. 2019;10:1310.

48. Branas CC, MacKenzie EJ, Williams JC, et al. Access to trauma centers in the United States. JAMA. 2005;293(21): 2626-2633.

49. Calero-Martinez SA, Matula C, Peraud A, et al. Development and assessment of competency-based neurotrauma course curriculum for international neurosurgery residents and neurosurgeons. Neurosurg Focus. 2020;48(3):E13. 
50. Kalkanis SN, Shaffrey CI, Rao G, et al. Letter to the Editor. Education and evidence-based medicine in neurosurgery. $J$ Neurosurg Spine. 2020;33(1):126-128.

\section{Disclosures}

Dr. Samadani reports receiving lecture fees from Abbott Laboratories, the American Association of Neuroscience Nurses, Cottage Health, Google Inc., Integra Corp., Medtronic Corp., National Neurotrauma Society, the National Football League, USA Football, and the Minnesota, Texas, Louisiana, and Wisconsin Coaches Associations; receiving grant support from the Minnesota Department of Education (Traumatic Brain and Spinal Cord Injury), Veterans Administration, Abbott Laboratories, Medtronic, and Integra; having equity in Oculogica; and serving as an unaffiliated neurotrauma consultant to the National Football League for 5 games during each of the 2015-2018 football seasons.

\section{Author Contributions}

Conception and design: Samadani, Rafter, Shen. Acquisition of data: Samadani, Rafter, Vasdev, Hurrelbrink, Gormley, Shen. Analysis and interpretation of data: Samadani, Rafter, Vasdev, Hurrelbrink, Shen. Drafting the article: Rafter, Vasdev, Hurrelbrink, Gormley. Critically revising the article: Samadani,
Rafter, Shen. Reviewed submitted version of manuscript: Rafter, Chettupally, Shen. Approved the final version of the manuscript on behalf of all authors: Samadani. Administrative/technical/ material support: Rafter, Chettupally. Study supervision: Samadani, Rafter, Shen.

\section{Supplemental Information}

Previous Presentations

Portions of this study were presented in poster form at the Annual Meeting of the Congress of Neurological Surgeons in San Francisco, California, on October 21, 2019.

\section{Correspondence}

Uzma Samadani: University of Minnesota, Minneapolis, MN. usamadan@umn.edu. 